\title{
Efektivitas Pemanfaatan Posyandu Lanjut Usia
}

\author{
Masluroh $^{1^{*}}$, Lili Farlikhatun ${ }^{2}$ \\ ${ }^{1,2}$ STIKes Abdi Nusantara Jakarta \\ *Email : imasluroh@yahoo.co.id
}

\begin{abstract}
Background: The elderly Posyandu is an integrated service post for the elderly that is driven by the community to be able to get health services. The coverage of elderly health services in Bekasi City in 2013 has generally reached the target. The RPJMD and SPM targets are 70\%, the health service achievement of the elderly reaches $84.2 \%$, but there are still Puskesmas that have not yet reached the target of one, Jati Bening Health Center. The purpose of this study was to determine the factors related to the use of elderly Posyandu.Methods: The place of research is in the working area of the Jatibening Health Center and was carried out in 2019. This study used an analytical survey method with a cross sectional approach. The population in this study are the elderly who are registered in the Posyandu of the elderly in the working area of the Jatibening Health Center totaling 100 people, a sample of 80 respondents using the Simple Random Sampling technique. Data collection by check list and questionnaire, the data is analyzed using univariate and bivariate analysis with Chi-square.Results: The results showed there was a relationship between the knowledge of the elderly (P 0.037), family support (0.0001), and the role of cadres (P 0.01) with the use of the elderly posyandu.Conclusion: From the results of the study it can be concluded that the factors of elderly knowledge, family support and the role of cadres in the use of elderly Posyandu greatly affect how the elderly Posyandu can be utilized properly, therefore researchers suggest for health workers to be able to improve health services by providing better health services and counseling the elderly about the benefits of posyandu for the elderly.
\end{abstract}

Keywords: utilization of elderly posyandu

\section{PENDAHULUAN}

Lanjut usia (lansia) adalah orang yang telah mencapai usia 60 tahun ke atas yang mempunyai hak yang sama dalam kehidupan bermasyarakat, berbangsa, dan bernegara (UU RI No 13 tahun 1998). Indonesia termasuk negara yang akan masuk ke penduduk struktur tua, karena persentase penduduk lanjut usia (lansia) yang telah mencapai $7,6 \%$ dari total penduduk (Sensus Penduduk, BPS 2010), dan diproyeksikan akan terus meningkat 306 buah dengan tingkat kemandirian pratama $(15,9 \%)$, madya $(40,3 \%)$, purnama $(39,9 \%)$ dan mandiri $(3,9 \%)$.

Berdasarkan Profil Kesehatan Kota Bekasi tahun 2013, Cakupan pelayanan kesehatan usia lanjut di Kota Bekasi tahun 2013 secara umum sudah mencapai target. Dari target RPJMD dan SPM pada tahun 2020-2035 seiring dengan Usia Harapan Hidup (UHH) Indonesia yang diproyeksikan akan terus meningkat dari 69,8 tahun (2010) menjadi 72,4 pada tahun 2035 (Bappenas, BPS, dan UNFPA, 2013).

Berdasarkan Data Sensus Penduduk 2010, jumlah penduduk lansia di Provinsi Jawa Barat berjumlah 547.412 orang (7,19\%). Kota Bekasi memiliki jumlah penduduk lansia sebanyak 27.751 orang $(5,41 \%)$, dan jumlah posyandu berjumlah sebesar $70 \%$, capaian pelayanan kesehatan lansia mencapai 84,2 \%. Namun jika kita lihat dari hasil di setiap Puskesmas, belum semuanya mencapai target. Puskesmas yang belum mencapai target karena kurang adanya kesadaran para usia lanjut untuk memeriksakan dirinya ke Posbindu atau tidak mau tau 
tentang kesehatan pribadinya. Puskesmas yang belum mencapai target diantaranya: Puskesmas Pondok Gede, Jati Makmur, Jati Bening, Teluk Pucung, Bintara, Pejuang, Bantar Gebang, dan Puskesmas Mustika Jaya.

Data prasurvey yang peneliti lakukan di posyandu lansia di wilayah kerja Puskesmas Jatibening pada bulan September 2018, peneliti mewawancarai 8 lansia, didapatkan hasil bahwa 3 orang $(37,5 \%)$ aktif dalam kegiatan posyandu lansia, sedangkan 5 orang lainnya $(62,5 \%)$ tidak aktif dengan alasan lansia tidak mengetahui tentang manfaat dan keberadaan posyandu sebagainya 2 orang, 2 orang karena kurang mendapat dukungan dari keluarga dan 1 orang karena kurangnya peran kader dalam pelaksanaan kegiatan posyandu lansia. Faktor-faktor yang mempengaruhi lansia tidak memanfaatkan posyandu lansia karena tidak adanya dukungan dari keluarga misalkan lansia diberikan beban untuk mengurus cucu selama anak mereka bekerja, lansia beranggapan di posyandu hanya ada pemeriksaan tensi dan timbang berat badan sedangkan yang mereka perlukan adalah pemeriksaan dari dokter.

Berdasarkan latar belakang maka penulis tertarik untuk meneliti tentang efektivitas pemanfaatan posyandu lansia.

\section{METODE PENELITIAN}

Penelitian ini menggunakan metode penelitian survey analitik dengan pendekatan cross sectional. Populasi dalam penelitian ini adalah lansia yang terdaftar di posyandu lansia yang berjumlah 100 lansia dengan sampel sebanyak 80 lansia. Teknik sampling yang digunakan adalah Simple Random Sampling. Pengumpulan data dengan cek list dan kuisioner, data dianalisis menggunakan analisis univariat dan bivariat dengan Chi-square.

HASIL PENELITIAN

Tabel 1. Distribusi Frekuensi Responden Berdasarkan Pengetahuan dengan Pemanfaatan Posyandu Lansia

\begin{tabular}{|c|c|c|c|c|c|c|c|c|}
\hline \multirow{3}{*}{ Pengetahuan } & \multicolumn{4}{|c|}{ Pemanfaatan Posyandu Lansia } & \multirow{2}{*}{\multicolumn{2}{|c|}{ Total }} & \multirow{3}{*}{$\mathbf{O R}$} & \multirow{3}{*}{$\begin{array}{c}\mathbf{P} \\
\text { Value }\end{array}$} \\
\hline & \multicolumn{2}{|c|}{ Tidak Aktif } & \multicolumn{2}{|c|}{ Aktif } & & & & \\
\hline & $\mathrm{N}$ & $\%$ & $\mathrm{~N}$ & $\%$ & $\mathrm{~N}$ & $\%$ & & \\
\hline Kurang & 13 & 68,4 & 6 & 31,6 & 19 & 100 & & \\
\hline Baik & 23 & 37,6 & 38 & 62,4 & 61 & 100 & 3,580 & 0,037 \\
\hline Jumlah & 36 & 45,0 & 44 & $\mathbf{5 5 , 0}$ & 80 & 100 & & \\
\hline
\end{tabular}

antara pengetahuan responden dengan pengetahuan kurang yang tidak pemanfaatan posyandu variabel memanfaatkan posyandu dan 23 orang pengetahuan dibagi menjadi 2 katagori (37,6\%) responden yang mempunyai yaitu kurang dan baik. Sedangkan pengetahuan baik namun tidak pemanfaatan posyandu juga dibagi memanfaatkan posyandu. Data lain menjadi dua, yaitu memanfatkan menunjukan sebanyak 623 orang $(31,6 \%)$ posyandu dan tidak memanfaatkan. Hasil mempunyai pengetahuan kurang namun analisis data menunjukkan angka 13 orang menggunakan posyandu, serta sebanyak 
38 orang $(62,40 \%)$ dengan pengetahuan baik yang memanfaatkan posyandu.

Hasil analisis data memperlihatkan nilai $p$ value 0,037 ( $p$ value $<0,05$ ), hal tersebut menunjukan bahwa ada hubungan pengetahuan responden dengan perilaku pemanfaatan posyandu.

Tabel 2. Distribusi Frekuensi Responden Berdasarkan Dukungan Keluarga dengan Pemanfaatan Posyandu

\begin{tabular}{|c|c|c|c|c|c|c|c|c|}
\hline \multirow{3}{*}{ Dukungan Keluarga } & \multicolumn{4}{|c|}{$\begin{array}{c}\text { Pemanfaatan Posyandu } \\
\text { Lansia }\end{array}$} & \multirow{3}{*}{\multicolumn{2}{|c|}{ Total }} & \multirow[t]{3}{*}{$\mathbf{O R}$} & \multirow{3}{*}{$\begin{array}{c}\mathbf{P} \\
\text { Value }\end{array}$} \\
\hline & \multicolumn{2}{|c|}{ Tidak Aktif } & \multicolumn{2}{|c|}{ Aktif } & & & & \\
\hline & $\mathbf{N}$ & $\%$ & $\mathbf{N}$ & $\%$ & & & & \\
\hline Tidak dapat dukungan & 28 & 71,8 & 11 & 28,2 & 39 & 100 & & \\
\hline Mendapat dukungan & 8 & 19,5 & 33 & 80,5 & 41 & 100 & 0,500 & 0,0001 \\
\hline Jumlah & 36 & 45,0 & 44 & 55,0 & 80 & 100 & & \\
\hline
\end{tabular}

Dari tabel 2 menunjukkan hubungan mendapatkan dukungan dari keluarga antara dukungan keluarga dengan yang memanfaatkan posyandu. Analisis pemanfaatan posyandu diperoleh data chi-square menunjukan angka $p$ value sebanyak 11 orang $(28,20 \%)$ yang tidak 0,0001 ( $p$ value $<0,05)$. Berdasarkan mendapatkan dukungan dari keluarga, nilai tersebut maka dapat disimpulkan ada namun memanfaatkan posyandu, serta hubungan antara dukungan keluarga sebanyak 33 orang $(80,50 \%)$ yang dengan pemanfaatan posyandu.

Tabel 3. Distribusi Frekuensi Responden Berdasarkan Peran Kader dengan Pemanfaatan Posyandu

\begin{tabular}{|c|c|c|}
\hline \multirow[t]{2}{*}{$\begin{array}{l}\text { Peran Kader } \\
\text { Posyandu }\end{array}$} & \multicolumn{2}{|c|}{$\begin{array}{l}\text { Pemanfaatan Po } \\
\text { Lansia }\end{array}$} \\
\hline & $\mathbf{N}$ & $\%$ \\
\hline Tidak ada peran kader & 9 & 81,8 \\
\hline Ada peran kader & 27 & 39,1 \\
\hline Jumlah & 36 & 45,0 \\
\hline $\begin{array}{l}\text { Dari tabel } 3 \\
\text { analisis data hubungan } \\
\text { kesehatan dengan pem } \\
\text { diperoleh data sebagai } \\
11 \text { orang merasa tidak } \\
\text { peran kader dimana } \\
\text { memanfaatkan posyar } \\
\text { memanfaatkanya. Dat } \\
59 \text { orang yang meras } \\
\text { peran kader, dimana } \\
\text { memanfaatkan posyan } \\
\text { orang memanfaatkan p }\end{array}$ & $\begin{array}{l}\text { erikl } \\
\text { i pe } \\
9\end{array}$ & $\begin{array}{l}\text { kan hasil } \\
\text { ran kader } \\
\text { posyandu } \\
\text { sebanyak } \\
\text { aruhi oleh } \\
\text { ng tidak } \\
2 \text { orang } \\
\text { enunjukan } \\
\text { aruhi oleh } \\
\text { ang tidak } \\
\text { gakan } 42\end{array}$ \\
\hline
\end{tabular}

\section{PEMBAHASAN}

Berdasarkan hasil penelitian dan teori diatas, maka dapat disimpulkan bahwa semakin tinggi pengetahuan lansia 
tentang manfaat dan keberadaan posyandu lansia, semakin meningkat pula jumlah lansia yang memanfaatkan posyandu. Sejalan dengan penelitian Widayanti (2012) di Puskesmas Banjar Agung, cakupan kunjungan posyandu lansia perbulan mencapai $55,7 \%$ dari 62 responden didapatkan $56,45 \%$ responden yang berpengetahuan kurang tentang posyandu lansia. Oleh karena itu, untuk meningkatkan pengetahuan lansia salah satunya dengan cara melakukan penyuluhan melalui kader-kader posyandu setempat, dengan sebelumnya para kader terlebih dahulu diberi pelatihan khusus tentang manfaat posyandu dan pentingnya keberadaan posyandu bagi lansia sehingga dengan adanya peningkatan pengetahuan oleh lansia diharapkan pemanfaatan posyandu akan berjalan dengan baik serta perlunya pemberian jadwal kegiatan secara terperinci setiap bulannya agar lansia dapat aktif mengikuti kegiatan sebagaimana yang telah tercantum pada jadwal kegiatan.

Berdasarkan hasil penelitian dan teori diatas, maka dapat disimpulkan bahwa semakin tinggi dukungan yang diberikan keluarga kepada lansia, semakin meningkat pula keaktifan lansia terhadap kegiatan di posyandu. Searah dengan penelitian Diana Maya Sari (2013) di Puskesmas Panaragan Jaya Kabupaten Tulang Bawang, didapatkan hasil dari 73 responden yang tidak mendapat dukungan dari keluarganya sebanyak 64 responden $(89 \%)$ dan yang mendapat dukungan sebanyak 8 responden $(11 \%)$ dengan $p$ value $=0,014$ yang berarti terdapat hubungan antara dukungan keluarga

dengan pemanfaatan posyandu usila di Puskesmas Panaragan Jaya Kabupaten Tulang Bawang. Oleh karena itu, keluarga hendaknya menjadi sarana bagi lansia dalam mengikuti kegiatan posyandu, selain itu perlunya penyuluhan kader posyandu kepada anggota keluarga agar pihak keluarga dapat mengetahui pentingnya manfaat posyandu sehingga tidak hanya lansia saja yang tahu akan manfaat posyandu tapi anggota keluargapun dapat mengetahui pentingnya posyandu bagi lansia, dengan demikian keluarga diharapkan mampu mengajak lansia untuk ikut serta dalam kegiatan posyandu lansia untuk meningkatkan kehadiran lansia diposyandu

Sebagaimana penelitian yang di lakukan oleh Misnawati Rujie (2013) mengenai " Hubungan Pengalaman dan Pelatihan Kader Terhadap Jalannya Posyandu Lansia Kecamatan Bukit Batu Kodya Palangkaraya".

Di dapatkan hasil bahwa Posyandu Lansia sangat berhubungan dengan pengalaman dan pelatihan yang di dapatkan oleh kader.Kemampuan kader baik ditinjau dari pendidikan dan pengetahuan kader harus dapat diaktualisasikan secara baik seperti dalam pemberian motivasi terhadap lansia agar mau untuk datang ke posyandu pada jadwal berikutnya kader harus mampu memberikan penjelasan atas pertanyaanpertanyaan dari lansia mengenai kesehatan. Hasil penelitian menunjukkan bahwa peran kader dinilai kurang oleh sebagian besar responden. Kondisi ini tidak lepas dari penilaian responden atas kinerja kader posyandu.

Penilaian yang kurang dari responden disebabkan karena kegiatan yang dilakukan di posyandu belum banyak perubahan yang dilakukan oleh para kader maupun petugas kesehatan untuk mau mengajak responden ataupun mau mendatangi ke rumah responden 
yang sudah lama tidak berkunjung ke posyandu lansia.

Kader posyandu diharapkan dapat meningkatkan perannya dalam kegiatan posyandu, dalam hal ini apabila sikap dan perilaku kader baik maka akan memperoleh penilaian yang baik dari peserta posyandu sehingga pemanfaatan posyandu dapat meningkat, sebaliknya apabila peran kader dinilai kurang baik, pemanfaatannya pun akan menurun dan lansia lebih memilih tempat pelayanan kesehatan lainnya yang dapat memberikan pelayanan lebih baik. Kader posyandu hendaknya dapat meningkatkan sikap, perilaku, serta pengetahuan tentang kesehatan agar lansia merasa nyaman berada dilingkungan posyandu sehingga nantinya akan terus aktif dalam kegiatan posyandu.

\section{KESIMPULAN DAN SARAN}

Berdasarkan hasil penelitian dan pembahasan, maka peneliti menarik kesimpulan bahwa belum maksimalnya pemanfaatan posyandu lansia, hal ini dapat dilihat dari data bahwa pengetahuan lansia terhadap pemanfaatan posyandu lansia dengan responden yang berpengetahuan baik $(76,2 \%)$, dukungan keluarga terhadap lansia dalam pemanfaatan posyandu lansia yaitu responden yang mendapatkan dukungan dari keluarganya (51,3\%), dan peran kader posyandu terhadap pemanfaatan posyandu lansia responden menilai sudah maksimalnya peran kader dalam kegiatan pemanfaatan posyandu lansia $(86,3 \%)$.

Dari hasil analisis bivariat dari ketiga faktor yang dihubungkan (faktor pengetahuan, dukungan keluarga dan peran kader) dengan pemanfaatan posyandu lansia mendapatkan hasil berhubungan ( $p$ value $<0,05)$.

\section{DAFTAR RUJUKAN}

Rujie, Misnawati. (2013). Hubungan Pengalaman dan Pelatihan Kader Terhadap Jalannya Posyandu Lansia Kecamatan Bukit Batu Kodya Palangkaraya. Fakultas Ilmu Kesehatan Universitas Diponegoro Semarang.

Sari, Diana Maya. (2013). Faktor-Faktor Yang Berhubungan Dengan Pemanfaatan Posyandu Usila Di Wilayah Kerja Puskesmas Panaragan Jaya Kecamatan Tulang Bawah Tengah Kabupaten Tulang Bawang. Karya Tulis Ilmiah. Poltekkes Tanjung Karang. Bandar Lampung.

Wahono, Hesthi. (2012). Analisis FaktorFaktor Yang Mempengaruhi Pemanfaatan Posyandu Lansia Di Gantungan Makamhaji. (2012) Skripsi. Fakultas Ilmu Kesehatan Universitas Muhammadiyah Surakarta.

Widayanti. (2012). Hubungan Pengetahuan dan Sikap Lansia terhadap Pemanfaatan Posyandu Lansia di Wilayah Kerja Puskesmas Banjar Agung. Fakultas Ilmu Kesehatan UMS Surakarta.

Kementrian Kesehatan Republik Indonesia. (2018). Profil Kesehatan Indonesia.

Dinas Kesehatan Kota Bekasi. (2014). Laporan Tahunan 2013. 